\title{
FORMAÇÃO DOCENTE E EDUCAÇÃO INCLUSIVA
}

\author{
LUIZ ANTONIO GOMES SENNA \\ Programa de Pós-Graduação em Educação da \\ Universidade do Estado do Rio de Janeiro \\ senna@senna.pro.br \\ http://www2.uerj.br/ proped
}

\begin{abstract}
RESUMO
Em que pesem os esforços recentes pela superação de estados de exclusão escolar, o mito do fracasso escolar persiste, impondo-se como mecanismo de banimento social e de perpetuação da condição de marginalidade em que vive grande parte da população brasileira, fato que compromete severamente a consecução do projeto nacional por uma educação inclusiva e emancipadora. Este texto analisa a natureza social do conceito de fracasso escolar, tomando-o como uma forma de banimento, cuja presença na escola é reforçada pela ausência de estudos teóricos sobre as bases do ensino em contextos de educação que acolham sujeitos marginais à cultura moderna. Neste sentido, discute-se o lugar de conhecimentos específicos na formação de professores e a necessidade de se resgatar o ensino como especialidade acadêmica, com base em uma abordagem que nos faça avançar e superar a concepção tecnicista que preponderou na educação formal à época da sociedade industrial.

FRACASSO ESCOLAR - FORMAÇÃO DE PROFESSORES - EDUCAÇÃO INCLUSIVA - ENSINO
\end{abstract}

\begin{abstract}
TEACHER EDUCATION AND INCLUSIVE EDUCATION. Regardless of recent efforts to overcome the school exclusion, the school failure myth persists and it imposes itself as a device for social banning and perpetuation of the marginalized condition in which the vast majority of the Brazilian population lives. It severely impairs the implementation of a national project for an inclusive and emancipating education. This text analyses the social nature of the school failure concept, considering it as a form of banning whose presence in the school is reinforced by the lack of theoretical studies about the foundations of teaching in contexts of education which host subjects who are at the margin of the modern culture. In this aspect, it discusses where specific knowledge stands in the education of teachers and the need to restore teaching as an academic speciality based on an approach which makes us advance and overcome the technicist conception which prevailed in formal education at the time of the industrial society.
\end{abstract} SCHOOL FAILURE - TEACHER EDUCATION - INCLUSIVE EDUCATION - TEACHING 
A área acadêmica da educação foi fortemente afetada pelas transformações científicas e sociais que marcaram o final do século passado. Em esfera mundial, os conceitos e paradigmas teóricos tradicionalmente compreendidos como base estável da educação formal sofreriam desde então forte abalo em sua credibilidade, fato que resultaria na introdução de novas vozes e convicções no universo acadêmico da educação e de todas as demais áreas a ela vinculadas de algum modo. Adventos como o resgate de concepções sociointeracionistas da mente - silenciadas por cerca de um século devido à ameaça que representavam para as fundações da sociedade moderna - e o surgimento de estudos em que as limitações do pensamento estruturalista buscavam se superar trariam transformações no perfil epistemológico da área de educação, ainda hoje não plenamente absorvidas pelos demais segmentos da cultura científica. Entretanto, paradoxalmente, no interior da área, ocorreria um substantivo prejuízo para as especialidades acadêmicas ligadas à questão da educação formal, notadamente no que se refere ao ensino.

Associado a práticas escolares diretamente determinadas pelos valores da sociedade industrial, o domínio acadêmico do ensino acabou por se dissolver, diante do que se pode denominar preconceito contra o tecnicismo, em boa medida decorrente de fatores que o justificam. Todavia, entre os fatores que caracterizam o ensino como objeto de um preconceito e o seu lugar na centralidade do processo de formação de professores há um hiato enorme, o qual justifica antes de tudo seu resgate, tanto do ponto de vista acadêmico, como no que se refere a sua posição nos currículos das licenciaturas. Sem perder de vista as demais justificativas, o que torna mais premente a retomada dos estudos sobre o ensino na sociedade brasileira contemporânea é o estado da educação formal (particularmente nas escolas públicas) diante da opinião pública, à medida que se vê ressurgir, e não sem despertar perplexidade, o mito do fracasso escolar como resultante de patologias. Assim, portanto, ressurge a medicalização do fracasso, justamente a situação que mais objetivamente se desejou superar, quando dos primeiros movimentos pela subversão da educação tecnicista, no século passado.

Neste trabalho, problematiza-se a situação atual do professor em face da demanda por uma educação de natureza comprometida com a inclusão social. Seu objetivo é, fundamentalmente, o de caracterizar os lapsos na formação do pessoal para o magistério, os quais têm determinado a perpetuação 
Formação docente...

do estado de fracasso escolar no país. Em um primeiro momento no texto, apresentam-se argumentos para uma definição do conceito de fracasso escolar como vinculado a um processo social que impõe o banimento de certos segmentos da população, historicamente sujeitos à situação de marginalidade. Nestes argumentos, deposita-se a intenção de anular - ou, se não tanto, fragilizar - o conceito público de que o fracasso escolar constitui uma categoria natural cuja adoção se pode tomar como parte de alguma predisposição, ou anomalia geradora da condição de excluído. Em seguida, o texto retoma a questão da formação de professores, analisando as causas recentes do preconceito contra o tecnicismo e o ensino, bem como as conseqüências objetivas para a educação inclusiva da descontinuidade do interesse sobre o ensino. Finalmente, situa o papel do professor na sociedade pós-industrial contemporânea, esboçando, com base nos objetivos da educação formal, a esfera de conhecimentos específicos que devem ser considerados nos currículos das licenciaturas.

\section{A CONSTRUÇÃO SOCIAL DO FRACASSO ESCOLAR}

Nos idos anos de 1980, o então governador do Estado do Rio de Janeiro viria a provocar enorme polêmica ao comparar os alunos de certo projeto de educação pública em regime de horário integral à figura de "porquinhos". Homem de formação rural, o governador não teve propriamente a intenção de depreciar os alunos, mas sua fala acionou um sem-número de mecanismos de defesa - até mesmo dentro de seu próprio governo - travestidos de indignação pela forma depreciativa como as crianças teriam sido qualificadas. Independentemente da óbvia constatação de que comparações, seja de crianças a porquinhos ou destes àquelas, ou ainda de governadores a burrinhos, nunca foram politicamente bem-vindas, a celeuma gerada em torno da questão eclodira de forma tão veemente em todo o país tão-somente porque, de fato, havia alguns porquinhos impregnados no conceito que a sociedade como um todo tinha dos alunos daquelas escolas públicas. Contexto análogo verificouse há poucos anos, já neste século, quando a Secretaria de Educação da cidade do Rio de Janeiro mudou o uniforme de seus alunos, adotando uma camiseta com detalhes cor laranja, uma espécie de cor oficial que passou a identificar todos os serviços vinculados à prefeitura, presente até mesmo em seu edifício 
sede. Contudo, era também a cor tradicionalmente empregada nos uniformes dos funcionários da companhia de limpeza urbana. À época, ninguém se ocupou de dizer que o prefeito havia pintado o palácio da cidade ou os carros dos secretários municipais na cor da Companhia Municipal de Limpeza Urbana Comlurb - e tudo foi absorvido como mais uma de suas excentricidades. Mas os uniformes dos alunos das escolas municipais, de pronto, tornaram-se um escândalo: onde já se viu vestir os alunos de garis?

Porquinhos ou garis - sem comparações, diga-se, a propósito -, vale a pena refletirmos sobre a motivação que tem levado a população do Rio de Janeiro, a exemplo do que ocorre no restante do país, a desejar ver sempre indícios pejorativos na figura dos alunos das escolas públicas. Decerto, não se trata, exatamente, de ver ou ouvir traços pejorativos nas falas dos governadores ou nos uniformes escolares, mas sim, de algo que, a priori, se define como um conceito de pessoa a se impor sobre a figura dos alunos, a todo momento pronto para se manifestar nas mais apuradas formas de preconceito, ainda que subvertidas em atitudes supostamente motivadas por intenções humanitárias. Isto significa que, antes de se ter anunciado a comparação entre alunos e porquinhos, ou antes de se os ter visto em uniformes similares aos dos garis, já existia um conceito social que os tomava como porquinhos ou como sujeitos sociais destinados a serem garis.

Em boa parte, a história do fracasso escolar no Brasil construiu-se em paralelo com a história do conceito social de sujeito das escolas públicas e dos preconceitos que, quero crer, inconscientemente, o povo brasileiro tem desejado perpetuar, dentro e fora da escola, por meio de inúmeros mecanismos de exclusão e banimento.

Embora aparentemente análogos, os atos de excluir e banir ganharam sentidos distintos na sociedade contemporânea, cujos institutos se organizam politicamente para assegurar o direito à inclusão social. Nos dias de hoje conta-se com um vasto aparato de expedientes legais e humanitários que visam a assegurar plenos direitos civis às minorias sociais, de forma que as práticas de exclusão tradicionalmente empregadas para interditar os ditos sujeitos marginais e mantê-los na condição de alienados da esfera pública colidem diretamente com os direitos que lhes são assegurados. Entretanto, ainda que potencialmente incluídos na sociedade, os marginalizados continuam a não ser tolerados e têm sua condição perpetuada na atitude social que os toma como sujeitos mera- 
Formação docente...

mente tutelados, cuja emancipação se compreende como impossível à luz de uma certa condição de alienado estrutural, ou seja, formalmente incapaz de ter comando sobre si próprio. Desse modo, às condutas de exclusão, vieram somar-se condutas de banimento, estas sutilmente organizadas para atestar e reiterar a natureza alienada dos sujeitos historicamente marginais.

fracasso escolar é produto, ao mesmo tempo, de uma vocação social para a exclusão e de um sem-número de mecanismos de banimento que reforçam a condição alienada dos sujeitos marginais, interditando-Ihes a possibilidade de serem sujeitos na esfera pública.

\section{Fracassos escolares e educação inclusiva}

A noção de "fracasso escolar" é ainda um tanto opaca na literatura acadêmica, visto que não se cuidou até hoje de defini-la apropriadamente. Isso se deve decerto ao fato de que, em ciência alguma, compreende-se como aparato teórico adequado alguma categoria que tome da frustração, da negação em si, como fenômeno objetivo. Do ponto de vista teórico, o fracasso escolar é tão-somente a negativa da educação formal e nada mais, de modo que se resumiria à definição genérica de algo como "não aprendizagem". A partir daí, sim, encontram-se inúmeros estudos sobre os famigerados problemas de aprendizagem, fundamentados em um elenco de distúrbios cognitivos, estes, por sua vez, devidamente categorizados na ordem da ciência. À medida que não se resolve a questão da opacidade na noção de fracasso escolar e, ao mesmo tempo, se incorporam à cultura da educação os diversos distúrbios de aprendizagem, a fim de explicar o comportamento dos alunos em situação de fracasso, incorremos em uma situação das mais perniciosas. Havemos de ter em conta que cada um dos chamados distúrbios de aprendizagem são definidos e categorizados segundo parâmetros oriundos de outras ciências, as quais tomam o homem como sujeito em desenvolvimento e não como aluno, que tem de aprender estes ou aqueles conteúdos escolares. O problema está, então, no fato de que a adoção dos inúmeros distúrbios de aprendizagem para explicar estados de fracasso escolar exige que se compreenda a experiência de ensino-aprendizagem da mesma forma que as demais ciências compreendem a experiência de desenvolvimento humano. Os conteúdos programáticos deixam, portanto, de ser saberes culturalmente motivados, para serem compreendidos como experiências essenciais de desenvolvimento. 
Em sua grande maioria, os estudos sobre os distúrbios de aprendizagem tomam por balizamento o pressuposto de que existem conteúdos escolares que devem ser ensinados e aprendidos, assim como o de que tais conteúdos são a matéria e a finalidade da educação formal. Nessa perspectiva, é possível levantar polêmica, indagando-se, por exemplo, qual a medida de aprendizagem que se pode considerar como satisfatória para não se identificar uma situação de fracasso escolar. Que quantidade de conteúdo programático um aluno deve ser capaz de expressar nos instrumentos de avaliação para não ser considerado um sujeito do fracasso escolar? Um aluno que na sua trajetória escolar tenha tirado notas cinco ou seis em todas as disciplinas é um sujeito do fracasso escolar? E o que dizer de outro que sempre tirou 10 nas avaliações de Língua Portuguesa e 2 nas de Matemática, tendo obtido média 6 quando se calcula a média das duas disciplinas?

Para nós, da educação, o fracasso escolar definitivamente não se situa na ordem da aprendizagem de conteúdos programáticos por eles mesmos, embora esta concorra para sua constatação sob certas circunstâncias. Nas reuniões de conselho de classe, a conduta socioafetiva do aluno concorre, muitas vezes, de forma mais preponderante para a constatação de fracasso escolar, do que o desempenho nas provas. Um aluno do tipo citado, com 10 em Língua Portuguesa e 2 em Matemática, poderá certamente ser isento do rótulo de fracassado escolar caso seja reconhecido como uma pessoa que apresente traços de socialização que atendam às expectativas de civilidade escolar, ao passo que outro, com idênticas notas, poderá ser rotulado como fracassado, caso sua conduta social não atenda a essas expectativas. Para este, evocam-se como causas do fracasso os distúrbios de comportamento, a versão socioafetiva dos distúrbios de aprendizagem.

É tudo muito relativo também na esfera dos distúrbios de comportamento. Normalmente, rotulam-se como tal apenas os casos de condutas que afetem a atenção concentrada ou interfiram na estabilidade da aula, provocando algum tipo de desordem. Raramente se arrolam na escola casos de sujeitos psicóticos, perversos e anti-sociais como casos de distúrbios de comportamento que afetem a aprendizagem, já que, de fato, não afetam. A menos que um sujeito psicótico desenvolva um padrão de comportamento que ameace a integridade física dos outros, sua conduta não perturba sua condição de aluno, até mesmo se seu comportamento magoar, humilhar, enfim, ameaçar a integridade moral do outro. 
Formação docente...

É, portanto, muito difícil definir o que vem a ser fracasso escolar com base nos distúrbios que têm sido utilizados para explicá-lo, já que a escola lida com certos padrões de tolerabilidade cuja natureza extrapola o conhecimento científico que descreve os distúrbios quando tomados em si mesmos. Em certa medida, o emprego do conhecimento científico pela escola, no momento em que se põe a explicar comportamentos de fracasso, não está isento de algum tipo de intenção de banir, ora com a finalidade de resgatar a normalidade do contexto de mundo ordinariamente compreendido como escola, ora com a de excluir aquele que se identifica como indesejável, ora ambos. Entre o crivo da incapacidade de aprender os conteúdos escolares e o da incapacidade de se ater aos padrões de comportamento ditos civilizados, existe uma margem de tolerância em que se separam os desejáveis dos indesejáveis, os redimíveis dos insuportáveis. Em regra, os alunos caracterizados como sujeitos do fracasso escolar são invariavelmente os indesejáveis e os insuportáveis. Os demais, ou são tratados como bem-sucedidos, ou, simplesmente, como apresentando traços peculiares que devem ser levados em conta no processo de avaliação.

A ambigüidade latente na noção de fracasso escolar, compartilhada por sujeitos sociais dentro e fora da escola, permaneceu como constante mesmo após a conclamação internacional por uma educação inclusiva, ética e formalmente comprometida com a meta de acolher, por meio da escolarização, os sujeitos historicamente marginais. Ainda que com bases motivacionais centradas na generalidade dos sujeitos sociais em demanda por inclusão, a educação inclusiva acabou sendo de imediato absorvida pela cultura da educação mediante uma percepção equivocada - não exatamente aleatória, porém motivada pela própria história de banimento promulgada pela escola - de que esta se pudesse reduzir à educação especial. De um lado até se pode compreender esta percepção como resultado de uma já longa e controversa discussão sobre incluir os deficientes na educação regular, ou mantê-los em instituições específicas, à margem das oportunidades de integração social que a escola lhes proporciona. Deste ponto de vista, a educação inclusiva ganharia vulto na área de educação especial como um marco no processo de desinterdição do deficiente e de sua integração ao mundo dos comuns. Por outro lado, no entanto, ao se restringirem os limites da educação inclusiva à questão da integração social dos deficientes, permitiu-se que a escola adentrasse a era da inclusão sem pre- 
cisar desconstruir os valores com que se vinha até então dando significado ao fracasso escolar, pois não se chegou a discutir o sujeito da educação inclusiva, limitado que foi, o processo político de inclusão, exclusivamente às esferas formal - legislativa e administrativa - e ético-social.

$\bigcirc$ outro lado da educação inclusiva, materialmente comprometido com a formação escolar dos sujeitos em demanda por inclusão social, permaneceu até os dias de hoje intocado, à medida que a margem de tolerabilidade para com as diferenças, intelectuais e sociais, continua a ser exatamente a mesma que sempre se aplicou à avaliação dos alunos. Aos deficientes e aos demais marginalizados sociais, estes que já se denominaram "deficientes culturais" nos anos mais rigorosos do estruturalismo, nada se ofereceu exceto o direito à vaga e à permanência no sistema de ensino. A superação da exclusão escolar demanda, no entanto, muito mais do que mero direito a vaga e permanência; demanda a superação dos valores que segregam e banem o indivíduo no cotidiano de uma experiência em que jamais conseguem superar os limites do intolerável, do fracasso eminente.

\section{O fracasso e a natureza social da escola}

A ambigüidade nos parâmetros que definem a condição de fracasso escolar está igualmente associada à definição social da instituição pública de ensino. As escolas públicas - supostamente laicas - surgem na sociedade moderna como coadjuvantes da família na formação da criança. Neste papel, ressalte-se, não preponderam os conteúdos formais de ensino, mas o desenvolvimento de um sem-número de padrões de comportamento reconhecidos e legitimados pelo modelo de sociedade que se vislumbrou possível e ideal na Modernidade, missão compartilhada tanto pela escola e pela família, como pelo próprio Estado. Falamos aqui de um tempo em que os próprios pais tinham como direito e dever banir do lar o filho, ou filha, que porventura se mostrasse indigno, ou ameaçasse a integridade moral da família. Falamos, portanto, de uma escola que, a exemplo da própria família, tinha por função banir as maçãs podres pelo bem da coletividade.

O conceito de família formadora encontra-se centralmente agregado aos valores que regulam a tolerância ao fracasso no contexto escolar, em boa medida vinculado, mais diretamente, à definição dos padrões de conduta a 
Formação docente...

serem considerados ou adequados, ou produtos de distúrbios de comportamento. Isso explica, por exemplo, por que se costuma associar o comportamento desviante à falta de educação familiar, a uma falha, portanto, no papel dos pais na formação dos alunos. E, por esse ponto de vista, também, se encontra alguma explicação para a justificativa de certos distúrbios de aprendizagem associados à falta de hábitos de estudos, cuja formação é igualmente delegada à família.

Na realidade, na escola o aluno é uma figura duplamente constituída, tendo em uma das faces o indivíduo e na outra a sua família, esta um sujeito não fisicamente presente, porém agregado ao próprio indivíduo. $O$ verdadeiro objeto do fracasso escolar são esses sujeitos intrincados um no outro, o aluno e sua família, ou, em outros termos, o aluno e sua natureza social. Não se trata, portanto, de uma concepção de fracasso que parta da análise do potencial cognitivo do sujeito como parâmetro universal e livre de interferência. Longe disso, parte-se do potencial da família, expresso no comportamento geral do aluno, ora mais, ora menos afeito a traços de natureza intelectual. Ainda que intelectualmente incapaz, um aluno é capaz de ser aprovado por intervenção de seu duplo familiar, à medida que este Ihe confira traços de aceitabilidade no meio escolar. Ao mesmo tempo, um indivíduo intelectualmente capaz pode ser reprovado, se a escola não identificar em seu duplo familiar, um sujeito escolar tolerável.

A título de exemplo, considerem-se os seguintes casos fictícios: (i) um aluno (A) desenvolve equivocadamente a solução de um problema de matemática envolvendo produtos notáveis, mas reproduz na resposta apresentada ao professor todo o conjunto de passos de raciocínio ensinados em aula, os quais, em princípio, conduziriam ao resultado correto; (ii) o aluno (B) desenvolve corretamente a solução do mesmo problema, mas adota mecanismos de raciocínio intuitivo não similares àqueles ensinados em aula, apresentando em sua resposta um conjunto de passos não reconhecidos pelo professor. Diante das duas respostas, o professor tende a privilegiar a resposta dada por (A), ainda que incorreta, sob o argumento de que esta apresenta um raciocínio adequado e compatível, e a rejeitar a resposta dada por (B), sob o argumento de que esta não apresenta um raciocínio adequado e compatível, fato que pode ter levado ao acerto por puro acaso. 
Embora aparentemente absurda, a conduta descrita é muito comum e plenamente absorvida pela cultura escolar, não somente na Matemática, mas em todas as disciplinas, levando-nos a concluir que a prática de ensinar transita simultaneamente entre as esferas do saber e do proceder. Saber qual a aplicação de um produto notável e empregá-lo de alguma forma eficaz para resolver uma determinada questão não é bastante para a cultura escolar. Contudo, a mera tentativa de resolver uma questão adotando-se procedimentos previamente ensinados para a solução de produtos notáveis pode bastar, ainda que não se chegue à resposta correta e não se tenha a menor idéia do conceito subjacente àqueles procedimentos. E o pior de tudo é que o aluno $(A)$ - que chegou ao resultado errado - raramente é associado à condição de fracasso escolar, ao passo que o aluno (B) - que chegou ao resultado correto - freqüentemente é.

Vale observar que, no mesmo caso citado, nem (A) nem (B) sofreram avaliação quanto ao tipo de raciocínio que propriamente desenvolveram na solução do exercício, pois na verdade ambos foram avaliados segundo um tipo de procedimento intelectual que deveria meramente reproduzir o modo de pensar que thes fora ensinado. A medida do fracasso, então, consiste em comparar o grau de aceitabilidade do raciocínio reproduzido e não em analisar o raciocínio do aluno. Por esse motivo, não é o indivíduo à frente do professor que está sendo avaliado. É a família subjacente ao indivíduo, que age como uma estrutura reguladora do grau de prontidão para o exercício de missão tão enfadonha como a de reproduzir um modo de pensar único, intransigente e alienante.

Ainda ao longo do século passado, a escola viria a incorporar metas de inclusão as mais radicais, desde os preceitos da obrigatoriedade escolar nos anos de 1970, aos de permanência de matrícula no anos de 1990. Sua natureza normativa confrontar-se-ia cada vez mais intensamente com um enorme contingente de alunos cujas famílias não se formaram segundo as bases sociais historicamente consagradas na tradição escolar. E do estranhamento entre os novos sujeitos escolares e as expectativas da escola desencadeou-se uma verdadeira indústria de fracasso escolar, que não se superaria mesmo quando ainda nos anos de 1980 - a escolas públicas despertaram para o fato de haver um domínio de relações em litígio entre escola e sociedade, cuja superação demandaria um novo olhar para os valores das relações professor-aluno. 
Formação docente...

\section{Fracasso e educação especial: da memória à facilitação do banimento social}

A tensão entre as margens de tolerabilidade da escola e o aluno tomado como duplo indivíduo-família apresenta-se de forma mais aguda ao longo do processo de alfabetização, fato que bem se pode constatar pela imensa horda de analfabetos e analfabetos funcionais atestados nos quatro cantos do país. Curiosa, todavia, é a persistência desse custo de alfabetização, mesmo após o advento de práticas de ensino motivadas e orientadas por bases conceituais diretamente comprometidas com o acolhimento das diferenças histórico-culturais e a com a busca pela construção da escrita, a começar pela promoção da descoberta de sua estrutura e função no interior das prerrogativas do ato comunicativo.

Ao longo da alfabetização parece haver menor espaço para a interveniência de aspectos subjetivos na avaliação do aluno, à medida que seu desempenho, em última instância, é julgado com base no tipo de comportamento que apresente quanto ao uso da escrita. Por esse motivo, mais freqüentemente do que nos demais estágios da formação escolar, as situações de custo na alfabetização costumam ser tratadas, ora como resultantes de inabilidade do professor, ora como absoluta incapacidade do próprio aluno, por imaturidade, ou por algum tipo de distúrbio, intelectual ou comportamental. A aparente facilidade no julgamento do sucesso ou do fracasso na alfabetização, tanto nas práticas ditas tecnicistas de alfabetização, quanto nas ditas construtivistas, embasadas na Psicogênese da Língua Escrita e suas variantes, pode esconder fatores outros, os mais complexos, na ordem das questões de que vimos tratando neste trabalho.

Ressalvo que quaisquer estudos sobre as possíveis causas do custo de alfabetização não devem ser interpretados como apelos à banalização da escrita, ou à formação de sujeitos letrados de forma precária. Ao contrário, o que se espera de tais estudos é a identificação de fatores a serem superados, para que o aluno venha a se apropriar da escrita como um sujeito social que dela se utilize para se comunicar plenamente em quaisquer situações de vida. A escola tem, irrecorrivelmente, a função de provocar a formação de sujeitos plenamente alfabetizados, sob pena de lhes furtar o direito de se apropriarem de tal tecnologia em seu próprio favor. Desse modo é preciso ter em conta que, entre os fatores hoje determinantes de custo na alfabetização, encontram-se fenô- 
menos que estão para além daqueles ordinariamente arrolados, seja entre as habilidades do professor, seja entre os distúrbios de desenvolvimento.

Considere-se ainda que a imensa maioria dos sujeitos em condição de fracasso na alfabetização encontra-se entre aqueles que podem ser classificados como em demanda por inclusão, oriundos das mais variadas formas de marginalidade. Este é, por si mesmo, um fato interessante, pois nos leva a refletir sobre duas hipóteses incabíveis: ou a imensa maioria dos professores que atua em contextos de educação inclusiva não tem formação adequada, ou uma imensa quantidade de brasileiros em situação de marginalidade apresenta severos distúrbios de aprendizagem.

Mais cabível é propor a hipótese de que o custo de alfabetização, dramaticamente vivido por inúmeros professores perante seus alunos, é uma construção acadêmico-social, algo que se explica pela mesma ordem de fatores que perpetua a ambigüidade nos parâmetros indicadores da condição do fracasso escolar. Algo que também perpassa a intolerância ao duplo familiar daquele aluno, cuja experiência cultural vê nas condições de produção da escrita uma violência tremenda a seus valores e formas de pensar, tornando-se, assim, ela própria, uma violência ainda maior em relação aos valores consagrados na cultura escolar.

Indiscutivelmente, a escrita não é mero ato de juntar letras segundo um código que associa letras a fonemas. Entretanto, também não resulta de um ajuizamento lógico de certa estrutura que se transponha da fala para a escrita, tal como pressupõem as correntes da alfabetização originárias no construtivismo e nas teorias discursivas. Fala e escrita são fenômenos lingüísticos distintos entre si e controlados por mecanismos mentais igualmente distintos. No domínio da comunicação falada, a oportunidade de interação imediata com o interlocutor permite ao sujeito adotar mecanismos mentais de estruturação e controle chamados narrativos, com baixo nível de planejamento e pouco controle lógico-seqüencial nas relações de coerência. Na escrita, por sua vez, tanto a ausência de interlocutor imediato, quanto as disposições formais determinadas pela estrutura canônica regulada por uma rígida norma social, não plenamente sujeita a interferências do ato comunicativo, exigem do sujeito a adoção de mecanismos mentais ditos científicos: sempre com alto nível de planejamento e elevado grau de controle lógico-seqüencial nas relações de coerência. É assim que sujeitos de culturas que atribuem pouco ou nenhum valor 
Formação docente...

ao modo científico do pensamento tendem ao fracasso na alfabetização, à medida que os mecanismos mentais por eles adotados na análise do fenômeno da escrita os levam à construção de um código não reconhecido como escrita pelas regras canônicas do código escrito formal. Não se trata de nenhum distúrbio de aprendizagem, mas é assim que o custo dos alunos costuma ser visto, apenando-se, ao mesmo tempo, o indivíduo e seu duplo familiar, sua cultura.

A zona de ambigüidade com que cultivamos a crença em uma suposta categoria de fracasso escolar na educação esconde, antes de tudo, uma zona de conhecimento que não se tem desejado conhecer, uma zona de experiências intelectuais e socioafetivas que reflete a condição cognoscente daqueles que a cultura moderna não deseja emancipar. Diante da ausência de fundamentos que expliquem como se estrutura o sujeito escolar em demanda por inclusão, resta ao professor balizar-se na normatividade que tradicionalmente fundou a história da exclusão escolar e do banimento social. Resta, portanto, à escola como um todo, reificar década após década o instituto das classes especiais, onde ano a ano aumentam os sujeitos do fracasso da alfabetização.

A base normatizante da educação formal contemporânea não deriva de expedientes advindos do cotidiano social. Ao contrário, este já apresenta traços que em muito redesenharam os parâmetros de integração e formação social, contando até com suporte legal que lhe dá amparo, mesmo sob circunstâncias inimagináveis um século atrás. A normatização da educação deriva daquilo a que se denomina normatividade do pensamento acadêmico, não uma norma propriamente a ser seguida, mas, sim, um padrão de normalidade subjetiva, com que se postula discriminar o certo e o errado, o que é senso comum e o que é contra-senso, enfim, o que é sujeito cognoscente e sujeito deficiente. Justamente na normatividade e sua condição de normalidade é que se situa o estado de estagnação da educação para a inclusão social.

Sujeitos não assimiláveis pela normalidade da razão moderna simplesmente não existem como possibilidade de sujeitos que aprendem na literatura que forma o professor, motivo pelo qual, especialmente na alfabetização, os estados gráficos manifestos pelos alunos em processo de alfabetização são considerados aberrações, anormalidades intelectuais. E assim, mesmo que sob o custo de seu próprio fracasso, o professor interdita o aluno na condição de anômalo e ajuda a perpetuar os mecanismos gerais de banimento. 
Ainda que um transtorno para os sistemas públicos de ensino, as classes especiais formadas por alunos que não se alfabetizam, hoje também chamadas de "classes de progressão" na cidade do Rio de Janeiro, são apenas mais um fenômeno afeito à suposta normalidade da sociedade moderna. Um lugar de porquinhos vestidinhos de garis.

\section{OS PROFESSORES E SUA FORMAÇÃO}

Desde os anos de 1970, a identidade profissional dos professores da educação básica no Brasil passa a sofrer com os reflexos das políticas públicas que promoveram uma repentina e necessária expansão da rede de ensino e uma progressiva ampliação da esfera de inclusão de novos sujeitos sociais, especialmente nas redes públicas. Logo nos primeiros anos após a promulgação da Lei n. 5.692/I97। - a Lei de Diretrizes e Bases da Educação Nacional que vigorou entre 197। e 1996 - o país se defrontaria com o problema de falta de professores para assistir a imensa rede de educação básica em nível fundamental, tanto no regime regular diurno, quanto no supletivo, noturno, uma situação que em algumas regiões do país significava a súbita triplicação da demanda regular por professores. Em paralelo ao custo financeiro que o novo perfil do quadro de professores traria de imediato para os cofres públicos, a implementação das metas de ampliação dos níveis de formação básica no país teria de pronto que superar a objetiva carência de profissionais formados e habilitados para o exercício do magistério. Tal estado de coisas traria conseqüências desastrosas.

Iniciava-se a partir daquela década um processo de paulatina degradação da identidade profissional do pessoal de magistério. $\bigcirc$ reflexo mais evidente e que se tornaria um clichê na sociedade foi a deterioração dos salários dos professores, deflagrado, ao mesmo tempo, pela impossibilidade de o poder público arcar com as despesas do quadro de pessoal recém-ampliado e pela cultura de educação como bem de consumo na rede privada. Entretanto, o processo de degradação instalou-se de forma mais perniciosa depois que o poder público - movido pelo interesse dos setores econômicos, dentro e fora da educação - tratou dos processos de formação de professores e de sua titulação. Para compor rapidamente o quadro docente necessário ao atendimento da rede ampliada, iniciou-se um processo de flexibilização de titulações, 
Formação docente...

que permitiria, por exemplo, o desvio de professores primários para o exercício do magistério do ensino fundamental, e, em paralelo, a autorização de funcionamento de cursos de formação de professores em regimes os mais precários, como as licenciaturas curtas, os cursos oferecidos em finais de semana, ou, simplesmente, cursos destinados a gerar mão-de-obra para o magistério, descompromissados com a qualidade ou com o desenvolvimento de profissionais efetivamente preparados para assumirem o projeto de inclusão escolar, desencadeado pelo dispositivo da obrigatoriedade escolar previsto na Lei n. $5.692 / 71$.

A questão da formação de professores agravou-se ainda devido à influência ideológica do regime militar até a primeira metade dos anos de 1980, quando os mecanismos vários de censura acabaram por impor aos projetos curriculares um tom mais técnico, conseqüentemente menos reflexivo, sobre a condição do agente de ensino. Disso resultou que, no lugar da construção de conhecimentos, o professor em formação recebeu informações sobre como ensinar, num movimento em que a metodologia do ensino e a engenharia técnica da mente humana preponderaram. Do ponto de vista acadêmico, uma educação estritamente baseada na metodologia do ensino pressupõe, é óbvio, algum tipo de embasamento capaz de sustentar a alegoria de uma formação que é mera alienação intelectual. Tal embasamento sustenta-se em dois pilares. O primeiro, consagrado na cultura moderna, a crença de que os conteúdos escolares têm propriedades edificantes por si mesmos e que sua aprendizagem é condição necessária ao pleno exercício da cidadania. $\bigcirc$ segundo, já não tão polêmico na cultura acadêmico-científica, a crença em um modelo de mente humana, universal e alijado de valor sociocultural, que explica como a metodologia de ensino pode ser empregada como uma forma de engenharia da aprendizagem, tanto formando genialidades humanas, quanto os anulando como sujeitos com desejos e identidade socioafetiva. Esse modelo de mente - inspirado nas contribuições de Jean Piaget - é formalmente sugerido no próprio corpo da Lei n. 5.692/7I e será por muitos anos parâmetro para a organização de todas as instâncias da escola, desde o planejamento das aulas e dos planos de cursos, as condições e instrumentos de avaliação, até os critérios de formação de turmas etc.

caráter tecnicista da formação docente de pronto demonstrou-se absolutamente inadequado para o exercício do magistério em contextos de inclu- 
são social, do que resultaram índices alarmantes de reprovação nas redes públicas de ensino, especialmente nas regiões em que as escolas atendiam preponderantemente à população historicamente segregada da sociedade. E não houve aí nada de extraordinário, já que é simplesmente inimaginável a missão de ensinar, quando se dispõe tão-somente de uma hipótese de engenharia humana que não prevê outros humanos que não os descritos na tradição da cultura moderna e, de um punhado de metodologias que se propõem a edificar aqueles cuja experiência de mundo os edificava de outro modo. Instalava-se, então, um impasse que ainda nos dias de hoje se impõe para os professores: o que empregar como fundamento no exercício profissional do magistério?

\section{Formação de professores nos dias atuais}

Como uma reação natural aos vários anos de pressão, os anos de 1980 trouxeram ao magistério um novo tom e o compromisso com o resgate da condição social da educação toma corpo nas escolas e nas salas de aula em todo o país. Fica então evidente para os professores que a parcela de contribuição dos conteúdos escolares para a formação dos alunos - especialmente nas escolas públicas - era, de fato, muito pequena, em relação ao enorme hiato que se impunha entre eles e o pleno exercício da cidadania. $\bigcirc$ magistério começa, a partir daí, a resgatar sua natureza fundamentalmente social e humanista, abraçando como um dever ético a causa da inclusão das minorias sociais. Ao mesmo tempo em que isso sucedia nas escolas e as revolucionava, chegava ao Brasil, ainda timidamente, a Psicogênese da Língua Escrita, mediante a qual se abriria espaço para um sem-número de outros estudos que criticavam severamente o modelo de mente previsto na Epistemologia Genética e resgatavam a condição social e cultural dos processos de construção de conhecimento.

A chegada de novos referenciais teóricos na educação ocorre simultaneamente ao final da Guerra Fria, juntamente, portanto, com um estado de certa perplexidade e ceticismo diante da cultura desenvolvida entre os séculos $X I X$ e $X X$, do que resultaria um movimento de limites não muito claros, denominado Pós-Modernidade. Por coincidência ou não, a Pós-Modernidade chega formalmente ao Brasil ao mesmo tempo em que este preparava uma série de pacotes para se ajustar à nova ordem econômica mundial. Então, sem ter plenamente conseguido dar conta dos problemas que se desencadearam 
Formação docente...

na década de 1970, o país promulga nova Lei de Diretrizes e Bases, em 1996, e reinaugura o mesmo tipo de problemas, desta vez em decorrência da necessidade de expansão da rede do ensino médio e da formação de professores primários em nível superior, substituindo por título de graduação a antiga titulação obtida em curso normal de nível médio.

Na prática, a vida do professor não mudou em nada... Nas salas de aula, no entanto, a condição de professor passa a antagonizar a condição de educador, o que em última instância significa que, para dar conta da absoluta incapacidade de ser professor com aquilo que a formação the oferecia, ele cede à situação de ser uma espécie de tutor social. A maioria dos professores hoje crê piamente, já nos primeiros dias de aula, que não vai conseguir ensinar nada, ou o mínimo o bastante, para seus alunos, preparando-se para mais um ano de magistério em que seus objetivos deslocam-se para a formação de hábitos sociais, de respeito ao próximo e de desenvolvimento de uma educação formal um tanto enviesada, meio que frustrante, tanto para os alunos como para si próprios.

No início dos anos de 2000, movida pelas disposições legais que propunham reformas nos currículos de formação de professores, a comunidade acadêmica, particularmente no âmbito da educação, viu-se diante da possibilidade de corrigir o lapso provocado pela orientação tecnicista do século passado. E entre discussões sobre o tempo mínimo de titulação, o regime de curso, a quantidade de horas de estágio, a solução de problemas quanto à adequação entre teoria e prática, enfim, sobre o modo de formação, passou ao largo a discussão essencial quanto ao saber que, objetivamente, o professor precisaria ter para se tornar agente de educação inclusiva.

A compreensão - a título ideológico ou não - de que uma formação estritamente técnica é prejudicial à formação do professor, com a qual compartilho, não resulta no mesmo que compreender a função do magistério como isolada de um conjunto de conhecimentos específicos para que se venha a cumprir a termo o ensino. Se, de um lado, o ensino estritamente baseado em uma metodologia acrítica provou-se absolutamente inadequado, de outro, que tipo de ensino o substitui hoje na escola básica? Se hoje o professor não mais é formado para reproduzir metodologias inócuas, como ele passou a se organizar para ensinar aquilo que ainda é sua obrigação ensinar como agente de educação básica? 
O que se constata é que a área de educação negligenciou profundamente o ensino como domínio de investigação e, ao torná-lo um objeto subsidiário, negligenciou também o estudo teórico sobre as condições de aprendizagem em contextos cujos sujeitos apresentem modelos cognitivos não assemelhados àquilo que, tradicionalmente, se acreditava ser padrão universal de funcionamento da mente. $O$ resultado foi um professor extremamente consciente e crítico de seu papel social, muitas vezes aberto ao diálogo com o universo conceitual de seus alunos, porém, absolutamente despreparado para intervir na qualidade de agente de educação formal. Assim o digam as turmas de progressão, ou seja lá qual termo se use para designar as classes especiais destinadas a alunos que não aprendem. E em paralelo às classes de progressão, renasce o surto de medicalização do fracasso escolar, mais uma vez imputando a supostas anomalias todo o universo de fatos que o professor e seus mestres desconhecem.

\section{O conhecimento que faltou e falta ao professor}

A breve história da alfabetização construtivista entre os anos de 1980 até hoje bem comprova a falência dos cursos de formação de professores. Curiosamente, quanto mais se adotam os preceitos da Psicogênese da Língua Escrita, mais se asseveram as dificuldades de alfabetização entre os sujeitos oriundos de culturas marginais. Não falo de situações experimentais, em que o pesquisador pode controlar e definir por si próprio onde chegar com o alfabetizando. Falo em situações concretas de vida escolar, nas quais o único ponto de chegada esperado e adequado é o uso da escrita, nos limites de aceitabilidade da norma canônica que a regula. É impossível crer em uma dislexia endêmica entre os pobres do país. É impossível também crer na possibilidade de superação desse estado de coisas com as práticas vigentes antes do construtivismo, uma vez que elas já se comprovaram inócuas no passado. A questão é outra. As bases teóricas do construtivismo foram absorvidas como tábuas de salvação e não como ponto de partida para outras investigações que, de fato, construíssem bases consistentes para o magistério.

Inúmeras questões permanecem ainda hoje pouco discutidas no domínio da educação, dentre as quais a mais significativa é o conceito operacional de zona de desenvolvimento proximal na esfera do ensino. $\bigcirc$ que significa o 
Formação docente...

termo "mediação"? Como se pode descrever formalmente para o professor os estados mentais que se produzem na zona de desenvolvimento proximal? Qual o conceito de aprendizagem que se deve ter na prática de ensino, quando se toma a aula como locus de estados de desenvolvimento proximal? Como se avalia isso?

Às questões anteriores deve-se acrescentar ainda uma outra, talvez a mais fundamental para o professorado: quem é o sujeito aprendente da educação inclusiva? Nesse "quem", compreendam-se dois sujeitos: o sujeito social, que ainda é um desconhecido pela escola, e o sujeito cognoscente, pois não cremos que, após duas décadas de sociointeracionismo, se possa sustentar alguma idéia de universalidade no modo pelo qual as pessoas pensam. Como ser professor, se não se tem como compreender como o aluno pensa e age? Como discernir entre um comportamento anômalo e um comportamento legitimamente desenvolvido para dar corpo e identidade a um sujeito social, em um contexto de mundo não previsto pela academia?

Uma vez que se espera do professor ser capaz de dispor sobre sua atuação profissional sem o controle de algum método que se imponha como ordem normativa do ensino, torna-se necessário que a ele seja conferido um conhecimento de tal ordem que preencha o espaço daquele saber, não expresso, porém subjacente ao método. $\bigcirc$ professor necessita, por exemplo, ser capaz de identificar os determinantes estruturais de um texto como ${ }^{A}\{$ uoco minevu la pa xoga pofenul $\}^{A}$, sem tratá-lo prontamente como um somatório de erros ortográficos imotivados e decorrentes do desconhecimento da escrita formal. Também não lhe basta assumir uma postura meramente solidária com textos como A, limitando-se a perguntar ao aluno o que ele quis dizer, assumir que este se encontra em desenvolvimento proximal e aguardar por algum desenvolvimento, isto porque, como se tem observado, corre-se o risco de tal aproximação perdurar indefinidamente. Entre $\mathrm{A}$ e algo como ${ }^{\mathrm{B}}\{\mathrm{O}$ maluco me levou lá para jogar (futebol) profissional $\}^{B}$, existem muito mais coisas do que se previra na teoria básica da Psicogênese. Existem duas formas de representação de mundo distintas, com direto impacto sobre a representação fonológica da mesma língua, o português. Do mesmo modo, assim como em C (a seguir), um sujeito, que teoricamente domina a escrita, pode produzir um texto não reconhecido como tal, em razão de the imprimir uma estruturação não adequada à escrita, mas à fala, em situações de comunicação em que o interlocutor pode intervir e solicitar as referências que não se expressam claramente. 
${ }^{c}\{$ Eles foram andando para o castelo. A menina também mas o vestido dela estava rasgado sabe. $O$ homem chegou aí todo mundo correu mas voltaram e o soldado também. Eu queria ser aquele soldado com cavalo. No dia seguinte tava chovendo o homem ficou bonzinho e eles vieram para casa de novo. $\}^{c}$

Contextos de educação intercultural - no caso brasileiro, a maioria absoluta das salas de aula, visto que as culturas escolar e extra-escolar mantêm grande diferença entre si - trazem para o professor inúmeras situações produzidas pelos alunos, em que se mesclam traços de sistemas estruturais e de valores não equivalentes entre si, do que resultam fenômenos como $\mathrm{A}$ e $\mathrm{C}$ apresentados. O sentimento de fracasso que o professor leva para a sala de aula e que o torna convicto de que não vai conseguir ensinar nada aos alunos ao longo do ano letivo associa-se mais a evidências como A e C, do que propriamente a situações que envolvem absoluta ausência de aprendizagem. Esse sentimento traduz-se em angústia, não propriamente pela evidência de A e C, mas pela ausência de resposta para o problema de como compreender o que leva à produção de tais evidências e como provocar sua superação.

$O$ enquadre teórico de situações como $A$ e $C$, nas quais se observam estados de aproximação entre culturas e seus respectivos sujeitos cognoscentes, exige um esforço de trabalho conjunto entre as especialidades acadêmicas do ensino básico e a educação. Àquelas cabe ir a campo para identificar e descrever todo o universo de representações produzido pelas culturas emergentes na sociedade moderna, objeto esse que, por exemplo, solucionaria o mistério que envolve a motivação fonológica de um texto como A. Para a educação, incluindo as demais ciências a ela aplicadas, cabe o estudo do modelo de ensino que permitiria à educação formal planejar e mediar com bases sustentadas a formação dos alunos em todos os níveis de ensino. Não se trata de resgatar o simplório e limitado universo do tecnicismo, mas, de reinventar o ensino, resgatando o lugar do professor na escola e na sociedade.

\section{A formação do professor e os objetivos da educação formal}

Os papéis que se desejam resgatar na figura do professor podem ser divididos em dois planos. No primeiro, situam-se os aspectos diretamente relacionados aos objetivos da educação formal no desenvolvimento do indivíduo, 
Formação docente...

aqueles que especificamente cabem à escola e não à educação informal, a cargo da família e da sociedade como um todo.

Na ausência de estudos consistentes acerca de tais objetivos, o professor tende a persistir na crença de que sua missão social consiste no ensino de conteúdos programáticos, uma crença das mais frágeis na sociedade contemporânea, dada a fartura de fontes de saber não ligadas à escola, como a TV e a internet. A bem da verdade, a escola há muito deixou de ser a fonte mais confiável de saber. Se pensarmos que, dentro dos próximos dez ou vinte anos, a maioria dos serviços que hoje dependem da escrita manual poderão vir a ser plenamente substituídos por tecnologias de processamento digital de voz, nem mesmo o rito da alfabetização será imprescindível para o pleno exercício da cidadania, de modo que já não se trata de um domínio curricular essencial na educação formal. Os saberes que povoam a escola hoje, sob severa margem de incredulidade dos alunos, tornaram-se circunstanciais, uma espécie de ferramenta on demand a que se tem acesso e de que se faz uso quando é necessária e, em seguida, retorna ao ciberespaço até nova demanda.

Os objetivos da educação formal situam-se para além dos conteúdos, na ordem de coisas que instaura as condições necessárias para se ter acesso ao saber e dele dispor de maneira satisfatória. Desse modo, o saber cede espaço ao conhecer, não como estado, porém como potencialidade humana, uma faculdade que proporciona ao homem tornar-se leitor do mundo. Não se confunda esse leitor com o objeto de trabalho dos professores de línguas. Tratase de um leitor que investiga, analisa, constrói hipóteses, avalia e transforma. Um sujeito que busca e elabora ferramentas materiais, sociais e intelectuais, e se projeta para o futuro, em busca de sua autonomia, sua emancipação. Para dar conta de seu próprio futuro, bem como de tudo mais que venha a desejar e conceber, até mesmo um texto, esse leitor necessita desenvolver a capacidade intelectual de ir além da percepção de mundo real, de ir ao encontro da abstração, seja como um devaneio lúdico, de onde possa experienciar o imaginário, seja como um planejamento formal, de onde surja o desenho de um ser possível mais adiante.

Além da formação do leitor de mundo, cabe à escola desenvolver no aluno a habilidade de transitar e operar tanto na esfera do mundo narrativo e suas representações incidentais, quanto na esfera do mundo científico, regido por relações de causalidade mais rígidas e quase nunca incidentais. Daí resul- 
ta, por exemplo, trabalhar a matemática como intuição (informal) e como linguagem formal, cada qual empregada em situações específicas. Trabalhar a fala e a escrita informal (como o "internetês"), bem como a escrita formal, igualmente empregadas nas respectivas situações específicas.

O segundo plano em que se situam os papéis do professor tem relação com sua formação própria para o magistério, envolvendo nesse caso, minimamente, os seguintes aspectos:

a. estudo das estruturas e propriedades que caracterizam o modo pelo qual os sujeitos pensam, percebem e interagem socialmente, em situações narrativas e científicas de leitura e interação com o mundo, por meio do qual o professor seja levado a não discriminar juízos e padrões de comportamento por serem diferentes dos seus próprios;

b. estudo de parâmetros para o planejamento da educação formal, tendo em conta a necessidade de o próprio professor ser capaz de integrar sua prática docente cotidiana a um projeto de formação de pessoas que perdura por onze anos, ao longo de toda a escola básica.

No âmbito do item b, situa-se sobretudo a demanda por um saber didático, um plano que, mais específico do que a prática de ensino, é preciso resgatar na formação dos professores, como dimensão que os leve a construir o conceito de aula. Um conceito que a tome como instância mediadora na formação de leitores de mundo, de planejamento do ensino como levantamento das perspectivas em torno das quais se institua o sentido (não propriamente a forma) da aula, assim como diversos outros aspectos específicos da profissão do magistério.

Encerro estas considerações não conclusivas, consciente de que o tema é muito polêmico no mundo acadêmico, pois há correntes que, direta ou indiretamente, negam a primazia de algum saber específico na formação docente. É preciso, contudo, trazê-lo à tona e começar a discernir entre o preconceito contra o saber meramente técnico e aquilo que é específico, necessário e imperativo para que a educação formal possa, de fato, cumprir-se numa perspectiva inclusiva. Caso contrário, estaremos tão-somente contribuindo para a 
Formação docente...

perpetuação da história social do fracasso escolar e deliberadamente contribuindo para a manutenção da condição de tutelados e interditados, desde sempre imputada aos sujeitos marginais em nossa sociedade.

\section{REFERÊNCIAS BIBLIOGRÁFICAS}

ADORNO, T. Educação e emancipação. Rio de Janeiro: Paz e Terra, 1995.

BERTICELLI, I. A Origem normativa da prática educacional na linguagem. ljuí: Unijuí, 2004.

BRINHOSA, M. A Função social e pública da educação na sociedade contemporânea. In: LOMBARDI, J. (org.) Globalização, pós-modernidade e educação-história, filosofia e temas transversais. Campinas: Autores Associados, 2002. p.39-60

CASE, R. Mudanças nas visões do conhecimento e seu impacto sobre as pesquisas e a prática educacional. In: OLSON, D.; TORRANCE, N. (eds.) Educação e desenvolvimento humano. Porto Alegre: Artes Médicas, 2003. p.73-91.

DANCY, J. Epistemologia contemporânea. Lisboa: Eds. 70, 1985.

FERREIRO, E. Reflexões sobre alfabetização. São Paulo: Cortez, 1995.

FERREIRO, E.; TEBEROSKY, A. Psicogênese da língua escrita. Porto Alegre: Artes Médicas, 1988.

GARIN, E. Ciência e vida civil no renascimento italiano. São Paulo: Unesp, 1995.

GLAT, R. A Integração social dos portadores de deficiência: uma reflexão. Rio de Janeiro: Sete Letras, 1995.

LIBÂNEO, J. Por uma pedagogia crítica que ajude na formação de sujeitos pensantes e críticos. In: LINHARES, C. et al. Os Lugares dos sujeitos na pesquisa educacional. Campo Grande: UFMT, 2002. p.72-85.

MAGALHÃES, J. Alquimias da escrita: alfabetização, história, desenvolvimento no mundo ocidental do Antigo Regime. Bragança Paulista: Ed.Universidade São Francisco, 200 I.

MORIN, E.; WULF, C. Planeta: a aventura desconhecida. São Paulo: Unesp, 2002.

NÓVOA, A. Formação de professores e profissão docente. In: NÓVOA, A. (org.) Os Professores e sua formação. Lisboa: Dom Quixote, 1997. p. I5-34.

OLIVEIRA. M. O Pensamento de Vygotsky como fonte de reflexão sobre a educação. Caderno Cedes, Campinas, v.20, n.35, p.9-14, jul. 2000. 
OLSON, D.; TORRANCE, N. Mudanças nas visões do conhecimento e seu impacto sobre as pesquisas e a prática educacional. Porto Alegre: Artes Médicas, 2000.

ORGANIZAÇÃO DAS NAÇÕES UNIDAS. CONFERÊNCIA GERAL, 28. Atas da... Nova lorque, 1995. v. I: Resoluções.

.CONFERÊNCIA MUNDIAL DE DIREITOS HUMANOS. Atas da... Nova

lorque, 1993.

OTTE, M. O Formal, o social e o subjetivo: uma introdução à filosofia e à didática da matemática. São Paulo: Unesp, 1993.

RIBEIRO, D. O Povo brasileiro: a formação e o sentido do Brasil. Rio de Janeiro: Companhia das Letras, 1995.

ROSCH, E.; LLOYD, B. B. Cognition and categorization. Hillsdale (NJ): L. Erlbaum, 1978.

ROSSI, P. A Ciência e a filosofia dos modernos. São Paulo: Unesp, 1992.

SACRISTÁN, J.; GOMÉZ, A. Compreender e transformar o ensino. Porto Alegre: Artmed, 1998.

SANTOS, B. A Crítica da razão indolente: contra o desperdício da experiência. São Paulo: Cortez, 2000.

SENNA, L. A. G. La Educación brasileña y sus múltiples supuestos. Revista de Educación, Madrid, n.321, p. 187-198, 2000.

Letramento e desarrollo humano en contextos educativos interculturales. In: CONGRESSO INTERNACIONAL VIRTUAL DE PSICOLOGIA EDUCATIVA. Islas Balleares: Universidad de las Islas Balleares, 200I.

Metáfora y sistemas complejos: la teoria lingüística e la descripción de estados de desarrollo proximal. In: CONGRESO INTERNACIONAL EDUCACIÓN, LENGUAJE Y SOCIEDAD, I. Actas. La Pampa (AR): UNLP, 2004. p. I - 12.

O Planejamento no ensino básico e o compromisso social da educação com o letramento. Educação \& Linguagem, São José dos Campos, n.7, p.200-2I 6, 2003.

Por una ciencia multicultural: la verdad como lenguaje proximal. In: ZARATE, J. Educación y desarrollo para el futuro del mundo. Vera Cruz (MX): Fesi, 2002. p.4l 0-4I7.

Psicogênese da língua escrita, universais lingüísticos e teorias de alfabetização. Revista ALFA, São Paulo, n.39, p.221-242, 1995.

Reflexões sobre mídias e letramento. In: ALVES, N.; OLIVEIRA, I.;

BARRETO, R. (orgs.) Pesquisa em educação: métodos, temas e linguagens. Rio de Janeiro: DP\&A, 2005. p. $161-174$. 
Formação docente...

SOARES, M. Escola e sociedade. São Paulo: Ática, 1984.

VERGER, J. Homens e saber na Idade Média. Bauru: Edusc, 1999.

VYGOTSKY, L. S. A Formação social da mente. São Paulo: Martins Fontes, 2000.

Pensamento e linguagem. São Paulo: Martins Fontes, 1998.

WADSWORTH, B. Inteligência e afetividade da criança na teoria de Piaget. São Paulo: Pioneira, 1997.

Recebido em: novembro 2006

Aprovado para publicação em: fevereiro 2007 